\title{
Indução de resistência no manejo da queima das folhas do inhame
}

\author{
Rodrigo Pereira Leite ${ }^{1}$, Luciana Cordeiro do Nascimento ${ }^{1} \oplus$, Erbs Cintra de Souza Gomes ${ }^{2}{ }^{\oplus}$, \\ Mônica Danielly de Mello Oliveira ${ }^{1}$ [C]
} ${ }^{1}$ Universidade Federal da Paraíba, Centro de Ciências Agrárias, Programa de Pós-Graduação em Agronomia, Campus II, Rod. PB 079 - Km 12 ,
s/n Campus Universitário, CEP 58397-000 Areia, Paraíba, Brasil. ${ }^{2}$ Instituto Federal do Sertão Pernambucano, Campus Petrolina Zona Rural - PE
647 Km 22 PISNC N - 4, Zona Rural Caixa Postal 277 CEP 56.302-970 Petrolina - PE, Brasil.

Autor para correspondencia: Mônica Danielly de Mello Oliveira (monicadmportella@hotmail.com)

Data de chegada: 17/07/2017. Aceito para publicação em: 30/01/2019.

$10.1590 / 0100-5405 / 182793$

\section{RESUMO}

Leite, R.P.; Nascimento, L.C.; Gomes, E.C.S.; Oliveira, M.D.M. Indução de resistência no manejo da queima das folhas do inhame. Summa Phytopathologica, v.46, n.1, p.31-35, 2020.

O objetivo do presente trabalho foi avaliar o efeito do extrato de Allamanda blanchetti (Ab) e do indutor de resistência acibenzolar-S-metil (ASM) no controle de Curvularia eragrostidis e na indução de mecanismos de resistência em mudas de inhame cv. São Tomé (Dioscorea alata). O isolado de $C$. eragrostidis foi obtido a partir de folhas de inhame com sintomas da doença. Crescimento micelial e esporulação do fungo foram avaliados por meio da adição dos tratamentos [extrato de $A$. blanchetti 10, 100, 500 e 1000 ppm, ASM (200 mg.L.-1), fungicida Mancozebe (200 g.ha ${ }^{-1}$ ) e testemunha composta por água destilada] ao meio BDA. Em casa de vegetação, mudas com 60 dias de idade foram pulverizadas com os tratamentos em ambas as faces da folha até o ponto de escorrimento, $\mathrm{n}$ os intervalos de 0,24, 48, 96 e $192 \mathrm{~h}$, seguindo-se a pulverização com suspensão de esporos $\left(1 \times 10^{5}\right.$ conídios. $\left.\mathrm{mL}^{-1}\right)$. A atividade das enzimas peroxidase, fenilalanina amônia liase (FAL) e $\beta$-1,3-glucanase foram analisadas em relação ao tempo de aplicação dos tratamentos. Não houve ação fungitóxica in vitro dos tratamentos a C. eragrostidis. O extrato de Ab e o ASM reduziram a incidência e a severidade da doença, bem como promoveram o aumento na atividade das enzimas peroxidases, FAL e $\beta$-1,3-glucanase, quando aplicados antes da inoculação com o patógeno. Estes resultados indicam o potencial de $A$. blanchetti no controle de $C$. eragrostidis em plantas de inhame pela ativação de mecanismos de defesa.

Palavras-chave: Dioscorea alata, Allamanda blanchetti, acibenzolar-S-metil, enzimas ligadas a patogênese

\section{ABSTRACT}

Leite, R.P.; Nascimento, L.C.; Gomes, E.C.S.; Oliveira, M.D.M. Induced resistance on the management of leaf blight in yam. Summa Phytopathologica, v.46, n.1, p.31-35, 2020.

The aim of this study was to evaluate the effect of both the extract from Allamanda blanchetti $(\mathrm{Ab})$ and the resistance inducer acibenzolar-S-methyl (ASM) on the control of Curvularia eragrostidis and on the induction of resistance mechanisms in seedlings of yam cv. São Tomé (Dioscorea alata). The isolate of C. eragrostidis was obtained from yam leaves with disease symptoms. Mycelial growth and sporulation were evaluated by adding treatments [extract of A. blanchetti 100, 500 and $1000 \mathrm{ppm}, \mathrm{ASM}\left(200 \mathrm{mg} \cdot \mathrm{L}^{-1}\right)$, fungicide Mancozeb ${ }^{\circledR}$ $\left(200\right.$ g.ha $\left.^{-1}\right)$, and control consisting of distilled water] to PDA medium. In a greenhouse, 60-day-old seedlings were sprayed with the treatments on both sides of their leaves to the point of runoff, at 0, 24, 48, 96 and 192h intervals, followed by spraying with a spore suspension $\left(1 \times 10^{5}\right.$ conidia. $\left.\mathrm{mL}^{-1}\right)$. The activity of peroxidases, phenylalanine ammonia lyase (PAL) and $\beta-1,3$-glucanase was analyzed in relation to the time of application of treatments. There was no in vitro fungitoxic action of treatments on C. eragrostidis. Extract of $\mathrm{Ab}$ and ASM reduced the disease incidence and severity and increased the activity of peroxidases, PAL and $\beta-1,3$-glucanase, when applied prior to inoculation with the pathogen. These results indicate the potential of $A$. blanchetti for $C$. eragrostidis control in yam plants by the activation of defense mechanisms.

Keywords: Dioscorea alata, Allamanda blanchetti, acibenzolar-S-methyl, pathogenesis-related enzymes.

O inhame (Dioscorea alata) tem grande importância alimentar na região Nordeste do Brasil, em virtude do seu alto valor nutritivo e energético $(10,22)$. No Estado da Paraíba, seu cultivo vem sendo intensificado nos últimos anos para atender a crescente demanda existente, principalmente para o mercado interno.

Não obstante à realidade das principais regiões produtoras de inhame do Brasil, vários são os registros de patógenos que infectam a cultura, tanto na parte aérea, interferindo na fotossíntese, como nas túberas, causando perdas na pós-colheita (19). Dentre os principais patógenos que afetam a cultura destaca-se, o fungo Curvularia eragrostidis (Henn.) Meyer, causador da queima das folhas, considerada a principal doença foliar do inhame no Nordeste brasileiro $(18,20)$.

A queima é uma doença de alta incidência e severidade, com registros de perdas em cultivos irrigados e de sequeiro. $\mathrm{O}$ crescimento da planta é significativamente reduzido e as folhas ficam retorcidas, apresentando um quadro típico de nanismo, resultando em perdas significativas de produção (7).

As limitações existentes à aplicação de defensivos agrícolas, aliados ao uso indiscriminado de fungicidas e a escassez de cultivares com características de resistência genética, fazem com que o desenvolvimento de novas tecnologias, principalmente a resistência induzida, represente uma alternativa viável no manejo das principais doenças nessa cultura (3).

Plantas medicinais possuem compostos secundários, compostos não vitais às plantas, mas com função de proteção contra pragas e doenças que tanto podem ter ação fungitóxica (ação antimicrobiana 
direta), como indutora, ativando mecanismos de defesa nas plantas (ação antimicrobiana indireta) $(16,19)$.

Na literatura é possível encontrar um grande número de trabalhos que utilizam as propriedades antimicrobianas dos compostos secundários de plantas medicinais para o controle de fitopatógenos $(3,21,23,25)$.

Algumas espécies de Allamanda spp. apresentam substâncias com ação antifúngica, dentre as quais se destacam os iridóides (13), bem como apresentaram resultados positivos na ativação dos mecanismos de defesa em Brassica oleracea (3). Diversos trabalhos comprovam o uso de ASM como indutor de resistência, principalmente ativando enzimas relacionadas à patogênese, como quitinase e $\beta$-1,3-glucanase. Esta ativação das enzimas está relacionado ao fato de que o ASM é um análogo ao ácido salicílico, o qual gera um sinal sistêmico de transdução de genes que codificam proteínas relacionadas a patogênese e enzimas relacionadas a produção de fitoalexinas e lignina $(4,11,15)$.

Face ao exposto, o presente trabalho objetivou estudar o potencial do extrato etanólico de Allamanda blanchetti e do indutor de resistância acibenzolar-S-metil no controle de Curvularia eragrostidis em mudas de inhame cv. São Tomé. e como fungicida natural.

\section{MATERIAL E MÉTODOS}

Os experimentos foram conduzidos no Laboratório de Fitopatologia e em casa de vegetação da Universidade Federal da Paraíba - UFPB, Departamento de Fitotecnia e Ciências Ambientais, Campus II, Areia, PB.

Folhas de $A$. blanchetti foram coletadas no povoado de Caboclo, município de Afrânio (PE), situado a 847'88'S e 4093'79”'W. Após a coleta, as folhas foram armazenadas em sacos plásticos e levadas para o Centro de Referência para Recuperação de Áreas Degradadas da Caatinga - CRAD na Universidade Federal Vale do São Francisco - UNIVASF em Juazeiro (BA), para processamento.

Após identificação, o material vegetal foi submetido à secagem em estufa a uma temperatura de $40{ }^{\circ} \mathrm{C}$ por $72 \mathrm{~h}$ e posteriormente triturado em moinho de facas para a obtenção de um pó fino e uniforme. Para a obtenção do extrato etanólico, utilizou-se o método de extração a frio, onde $150 \mathrm{~g}$ do pó de $A$. blanchetti, imerso em $150 \mathrm{~mL}$ de etanol absoluto durante 72 hem temperatura ambiente. Após o procedimento, o extrato foi reduzido em evaporador rotativo por $2 \mathrm{~h}$ a $78^{\circ} \mathrm{C}(5) . \mathrm{O}$ extrato bruto foi diluído nas concentrações $10,100,500$ e 1000 ppm para serem utilizadas no experimento.

O isolado de C. eragrostidis foi obtido a partir de folhas de inhame com sintomas característicos da doença, coletadas em áreas de produção comercial no município de Areia, PB.

$\mathrm{O}$ extrato de $A$. blanchetti foi incorporado ao meio BDA, nas concentrações de 10, 100, 500 e 1000 ppm, além do tratamento ASM (200 mg.L $\left.\mathrm{L}^{-1}\right)$ e fungicida Mancozeb ${ }^{\circledR}\left(200 \mathrm{~g}^{\mathrm{h}} \mathrm{ha}^{-1}\right)$. Discos com $7 \mathrm{~mm}$ de diâmetro contendo colônia do fungo foram transferidos para o centro das placas de Petri e mantidas durante sete dias a $25 \pm 2{ }^{\circ} \mathrm{C}$ e fotoperíodo de 12 horas.

As avaliações do crescimento micelial foram realizadas através de medições diárias do diâmetro das colônias de forma diametralmente oposta, utilizando-se paquímetro digital. As avaliações foram realizadas até o momento em que a testemunha ocupou todo o diâmetro da placa.

Após a avaliação do crescimento micelial, verificou-se a esporulação a partir de uma suspensão de esporos, obtida pela adição de $10 \mathrm{~mL}$ de água destilada esterilizada (ADE) nas placas contendo colônias puras de C. eragrostidis. Posteriormente, realizou-se a raspagem da colônia com escova de cerdas macias e filtragem em dupla camada de papel de filtro, sendo determinado o número de esporos em câmara de Neubauer. Os resultados foram expressos em número de esporos por $\mathrm{cm}^{2}$ de colônia.

Em casa de vegetação, foram utilizadas mudas oriundas da semeadura de túberas-sementes de inhame cv. São Tomé (D. alata) com 60 dias de idade e padrão uniforme. As mudas foram plantadas em vasos com capacidade de 10L, utilizando como substrato terra vegetal, areia lavada e esterco bovino na proporção de $2: 1: 1$, respectivamente e mantidas em temperatura ambiente $\left(27 \pm 2{ }^{\circ} \mathrm{C}\right)$. Decorrido o período de semeadura, foi realizada uma aplicação foliar dos tratamentos, respeitando-se os intervalos de tempo: $0 \mathrm{~h}(\mathrm{P} 5), 24 \mathrm{~h}(\mathrm{P} 4), 48 \mathrm{~h}(\mathrm{P} 3), 96$ h (P2) e 192 h (P1) antes da inoculação de C. eragrostidis. Foi utilizada também uma testemunha pulverizada com ADE, fungicida Mancozeb ${ }^{\circledR}$ (200 g.ha $\left.{ }^{-1}\right)$ na e ASM (200 mg.L $\left.\mathrm{L}^{-1}\right)$.

Os tempos de coleta das amostras para verificação das respostas de defesa foram 0, 24, 48, 96 e 192 h após a aplicação dos tratamentos. Posteriormente, o material vegetal foi imerso em nitrogênio líquido, identificado e acondicionado em caixas isotérmicas, e transportado ao Laboratório de Química Orgânica e Bioquímica vegetal da Universidade Federal do Vale do São Francisco - UNIVASF em Juazeiro (BA), para determinação das atividades de peroxidase, fenilalanina amônia liase (FAL) e $\beta, 1,3$ - glucanase.

Amostras de folhas foram pesadas e maceradas na presença de nitrogênio líquido, usando almofariz e pistilo e, em seguida, homogeneizadas com $5 \mathrm{~mL}$ de tampão acetato de sódio a $100 \mathrm{mM}$ (com EDTA a 1mM, PVPa 1\% da solução tampão e pH 5,0). A solução resultante foi transferida para microtubos de $1,5 \mathrm{~mL}$ e centrifugada a $2000 \mathrm{~g}$ durante 25 minutos a $4{ }^{\circ} \mathrm{C}$. Uma vez centrifugada, a solução sobrenadante, considerada como extrato enzimático, foi transferida para novos tubos e armazenada em freezer a $-20^{\circ} \mathrm{C}$.

A atividade de peroxidase foi determinada pelo método de espectrofotometria direta, pela medida de conversão do guaiacol em tetraguaiacol a $470 \mathrm{~nm}$. A mistura da reação continha $1 \mathrm{~mL}$ de tampão acetato de sódio $0,1 \mathrm{M}, 250 \mu \mathrm{L}$ de peróxido de hidrogênio $(0,38 \mathrm{M}), 50$ $\mu \mathrm{L}$ de guaiacol e $250 \mu \mathrm{L}$ do extrato protéico. A atividade de peroxidases foi expressa como atividade específica em unidade de absorbância. $\min ^{-1} . \mathrm{g}$ de peso fresco (6).

Na quantificação da FAL, $250 \mu \mathrm{L}$ de cada amostra foram transferidos para tubos de ensaio. Adicionou-se $1,0 \mathrm{~mL}$ de solução tampão TRISEDTA $(0,5 \mathrm{M} \mathrm{pH} 8,5)$ e $250 \mu \mathrm{L}$ de solução de L-fenilalanina como substrato a uma concentração de $300 \mu \mathrm{L} \cdot \mathrm{mL}^{-1}$. A reação foi incubada por $1 \mathrm{~h}$ a $40^{\circ} \mathrm{C}$ em banho-maria. Após esse período, a reação foi paralisada em banho de gelo, sendo realizada a leitura da absorbância da reação a $290 \mathrm{~nm}$ em espectrofotômetro, com os valores expressos em g/mL de ácido trans-cinâmico (2).

A atividade de $\beta$-1,3-glucanase foi medida pelo aumento dos grupos redutores de açúcares, usando como substrato a laminarina, sendo que uma unidade do grupo redutor foi definida como quantidade de enzima capaz de liberar $1 \mathrm{mM}$ de glicose em $1 \mathrm{~min}$ a $40^{\circ} \mathrm{C}$. Na quantificação de $\beta-1-3$, glucanase, $150 \mu \mathrm{L}$ do extrato enzimático e $150 \mu \mathrm{L}$ de tampão

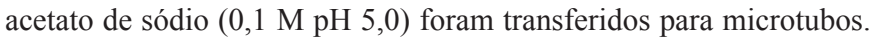
Utilizou-se $150 \mu \mathrm{L}$ de Laminarina como substrato a uma concentração $4,0 \mathrm{mg} \cdot \mathrm{mL}^{-1}$. A reação foi incubada por $1 \mathrm{~h} \mathrm{a} 40^{\circ} \mathrm{C}$ em banho-maria. Após esse período, a reação foi paralisada utilizando-se $200 \mu \mathrm{L}$ de fenol a $5 \%$ e $100 \mu \mathrm{L}$ de ácido sulfúrico concentrado. Posteriormente, foram realizadas leituras em espectrofotômetro a $480 \mathrm{~nm}$ e comparadas com padrões de glicose. A curva padrão de glicose utilizada foi constituída 
das seguintes concentrações $0,5,10,20,40,80,160 \mu \mathrm{g} \cdot \mathrm{mL}^{-1}(14)$.

O delineamento experimental foi DIC composto por sete tratamentos: quatro concentrações do extrato etanólico (10, 100, 500 e 1000 ppm), ASM; fungicida Mancozeb ${ }^{\circledR}$ e uma testemunha (ADE), com cinco repetições compostas por uma muda. A análise enzimática constou de três repetições, em triplicata. Os dados foram submetidos à análise de variância, teste $\mathrm{F}$ e as médias comparadas pelo teste de Tukey a $5 \%$ de probabilidade.

\section{RESULTADOS E DISCUSSÃO}

Os resultados obtidos da avaliação do percentual de inibição do crescimento micelial e do percentual de inibição da esporulação de C. eragrostidis pelo extrato etanólico de $A$. blanchetti podem ser observados na tabela 1.

As concentrações do extrato etanólico de $A$. blanchetti e ASM não apresentaram ação fungitóxica, não inibindo o crescimento micelial e não diferindo significativamente da testemunha e nem do fungicida.

Também não foi verificado efeito das concentrações do extrato de $A$. blanchetti e ASM sobre a esporulação de C. eragrostidis. Não houve diferença significativa $(\mathrm{P}>0,05)$ entre todas as concentrações do extrato, ASM e fungicida em relação à testemunha. Os dados obtidos neste trabalho não corroboram com Barros et al. (3), que utilizaram as mesmas concentrações do extrato de $A$. blanchetti e, observaram ação antimicrobiana direta no controle de Alternaria brassicicola em mudas de couve-manteiga (Brassica oleracea L. var. acephala).

Estudos têm demonstrado o potencial de extratos de Allamanda spp. no controle de patógenos vegetais. Domingues et al. (9) verificaram inibição total do crescimento micelial de Colletotrichum acutatum pelo extrato de $A$. cathartica, mostrando sua atividade fungitóxica sobre este patógeno. $\mathrm{O}$ extrato de $A$. blanchetti reduziu significativamente o crescimento do fungo Rhizopus stolonifer na microflora de sementes de Clitoria fairchildiana (17). Os extratos de $A$. cathartica inibiram em $100 \%$ o crescimento micelial de Phomopsis vexans (1).

Os resultados obtidos no presente trabalho demonstraram haver diferentes níveis de pré-condicionamento nas plantas em reposta à utilização dos tratamentos, refletidos na expressão da atividade enzimática avaliada. De modo geral, constatou-se uma baixa atividade de peroxidase em mudas de inhame tratadas com extrato de $A$.
Tabela 1. Inibição in vitro do crescimento micelial e da esporulação de Curvularia eragrostidis em função do tratamento com extrato etanólico de Allamanda blanchetti

\begin{tabular}{lcc}
\hline \multirow{2}{*}{ Tratamentos } & \multicolumn{2}{c}{ Inibição (\%) } \\
\cline { 2 - 3 } & Crescimento micelial & Esporulação \\
\hline Ab 10 ppm & $10,6 \mathrm{a}$ & $33,48 \mathrm{a}$ \\
$\mathrm{Ab} 100 \mathrm{ppm}$ & $10,4 \mathrm{a}$ & $29,27 \mathrm{a}$ \\
$\mathrm{Ab} 500 \mathrm{ppm}$ & $10,6 \mathrm{a}$ & $42,83 \mathrm{a}$ \\
$\mathrm{Ab} 1000 \mathrm{ppm}$ & $10,8 \mathrm{a}$ & $25,21 \mathrm{a}$ \\
ASM & $10,2 \mathrm{a}$ & $22,75 \mathrm{a}$ \\
Fungicida & $9,0 \mathrm{a}$ & $30,65 \mathrm{a}$ \\
Testemunha (ADE) & $0,0 \mathrm{a}$ & $12,48 \mathrm{a}$ \\
\hline DMS & 11,51 & 43,64 \\
\hline
\end{tabular}

* Médias seguidas de letras diferentes nas colunas diferem entre si pelo teste de Tukey a $5 \%$ de probabilidade $(\mathrm{P}<0,05)$. Ab - Extrato etanólico de Allamanda blanchetti extraído a frio (nas concentrações de $10,100,500$ e $1000 \mathrm{ppm}$ respectivamente), ASM - produto comercial acibenzolar-S-metil (ASM), fungicida $\left(\right.$ Mancozeb $\left.^{\circledR}\right)$ e testemunha - água destilada e esterilizada (ADE).

blanchetti. No entanto, foram observadas diferenças significativas em relação à testemunha $(\mathrm{ADE})$.

No tempo $192 \mathrm{~h}$ (P1), O maior nível de atividade de peroxidase foi observado em mudas tratadas com ASM, com diferença significativa dos demais tratamentos, evidenciando um estádio de pré-condicionamento das plantas à expressão de diferentes níveis de seus mecanismos de defesa (Tabela 2). Em P2 (96 h), não houve diferença na ativação da peroxidase entre os tratamentos e a testemunha.

Para o intervalo P3 (48 h), o tratamento com Ab 1000ppm foi o que proporcionou máxima atividade enzimática, seguido do ASM e do fungicida todos com diferença significativa em relação à testemunha. Já em P4 (24 h) e P5 (0 h), Ab 1000ppm e Ab 500 ppm foram os tratamentos que proporcionaram maiores níveis de atividade enzimática com diferença significativa dos demais tratamentos.

Segundo Boava et al. (6) o aumento da atividade da enzima pode estar relacionado à capacidade do ASM de ativar mecanismos de defesa

Tabela 2. Atividade de peroxidases em folhas de inhame, a partir do tratamento com diferentes concentrações do extrato etanólico de Allamanda blanchetti, acibenzolar-S-metil e fungicida em diferentes intervalos de aplicação. Areia, PB 2011

\begin{tabular}{|c|c|c|c|c|c|}
\hline Tratamentos & \multicolumn{5}{|c|}{ Intervalo de aplicação $^{1}$} \\
\hline $\mathrm{Ab} 10 \mathrm{ppm}$ & $0,000 \mathrm{c}$ & $0,001 \mathrm{a}$ & $0,000 \mathrm{~cd}$ & $0,000 \mathrm{~b}$ & $0,000 \mathrm{~d}$ \\
\hline $\mathrm{Ab} 100 \mathrm{ppm}$ & $0,000 \mathrm{c}$ & $0,000 \mathrm{a}$ & $0,000 \mathrm{e}$ & $0,000 \mathrm{~b}$ & $0,000 \mathrm{~d}$ \\
\hline Ab 500 ppm & $0,000 \mathrm{c}$ & $0,000 \mathrm{a}$ & $0,000 \mathrm{de}$ & $0,000 \mathrm{~b}$ & $0,008 \mathrm{a}$ \\
\hline $\mathrm{Ab} 1000 \mathrm{ppm}$ & $0,000 \mathrm{c}$ & $0,002 \mathrm{a}$ & $0,112 \mathrm{a}$ & $0,004 \mathrm{a}$ & $0,001 \mathrm{c}$ \\
\hline Fungicida & $0,002 \mathrm{c}$ & $0,002 \mathrm{a}$ & $0,001 \mathrm{bc}$ & $0,000 \mathrm{~b}$ & $0,000 \mathrm{~d}$ \\
\hline Testemunha & $0,005 \mathrm{~b}$ & $0,000 \mathrm{a}$ & $0,000 \mathrm{de}$ & $0,000 \mathrm{~b}$ & $0,002 \mathrm{~b}$ \\
\hline DMS & 0,003 & 0,002 & 0,0005 & 0,0014 & 0,0006 \\
\hline
\end{tabular}

*Medias seguidas das mesmas letras não diferem entre si na coluna (minúsculas) pelo teste de Tukey a 5 \% de probabilidade. P1, P2, P3, P4 e P5 períodos em horas $(192,96,48,24,0$ respectivamente) entre a aplicação dos tratamentos e a inoculação com o patógeno. Concentrações utilizadas: 10, 100, 500 e 1000 ppm (Ab), $200 \mathrm{mg} . \mathrm{L}^{-1}(\mathrm{ASM})$ e $250 \mathrm{~g}^{\mathrm{h}} \mathrm{ha}^{-1}$ (Mancozeb ${ }^{\circledR}$ ), respectivamente. 
das plantas, antecipando prováveis reações bioquímicas de defesa que só seriam ativadas na presença de um patógeno. A ativação de peroxidasesé um indício de indução de resistência, haja vista que estas enzimas atuam na ação preventiva contra a penetração de patógenos por ação oxidativa de componentes da parede celular vegetal (24).

Com base nos resultados obtidos, pode-se afirmar que o ASM teve sua máxima expressão enzimática, quando aplicado com $192 \mathrm{~h}$ (P1) antes da inoculação de C. eragrostidis. Já no caso do extrato de Allamanda é necessário um período menor entre a aplicação e o desafio com o patógeno, sendo que $\mathrm{Ab} 1000 \mathrm{ppm}$, foi o tratamento, com maior atividade enzimática quando aplicado nos intervalos P3 e P4.

O princípio da indução de resistência baseia-se num "desafio" a planta antes da inoculação do patógeno, para que neste momento os mecanismos de defesa sejam ativados e a planta possa se defender com eficiência. Para Kuhn (15) em uma planta pré-condicionada a intensidade das alterações metabólicas desencadeadas a partir da chegada do patógeno é fator determinante para a ativação de respostas de defesa ao ataque do patógeno.
Na determinação da atividade enzimática de $\beta$-1,3-glucanase observou-se um aumento relativo até $24 \mathrm{~h}$ após a pulverização em todas as concentrações do extrato de Allamanda, ASM e fungicida. As plantas pulverizadas com esses tratamentos nos intervalos $\mathrm{P} 1$, P2 e P3, apresentaram efeitos na atividade de $\beta$-1,3-glucanase, porém sem apresentar diferença entre os tratamentos e a testemunha (Tabela 3).

Dentre os indicativos de ativação de respostas de defesa de plantas a partir da aplicação de elicitores, as enzimas peroxidase e $\beta$-1,3-glucanase são as principais (8). Segundo Govindappa et al. (12) há relação entre a atividade sinérgica da $\beta$-1,3-glucanase e a via da resistência sistêmica adquirida (RSA) que inclui o ácido salić́lico como molécula sinalizadora e a qual é ativada pelo reconhecimento de patógenos e indutores químicos.

A atividade da FAL em plantas de inhame foi influenciada tanto pelos tratamentos como pelos períodos de aplicação e posterior inoculação do patógeno. Plantas tratadas com extrato etanólico de A. blanchetti, independente da concentração utilizada, apresentaram

Tabela 3. Atividade de $\beta$-1,3-glucanase a partir de diferentes concentrações do extrato etanólico de Allamanda blanchetti em diferentes intervalos de aplicação. Areia - PB, 2011.

\begin{tabular}{|c|c|c|c|c|c|}
\hline Tratamentos & \multicolumn{5}{|c|}{ Intervalo de aplicação $^{1}$} \\
\hline $\mathrm{Ab} 10 \mathrm{ppm}$ & $0,490 \mathrm{a}$ & $0,432 \mathrm{a}$ & $0,402 \mathrm{a}$ & $0,353 \mathrm{a}$ & $0,326 \mathrm{a}$ \\
\hline Ab 100 ppm & $0,504 \mathrm{a}$ & $0,485 \mathrm{a}$ & $0,420 \mathrm{a}$ & $0,326 \mathrm{a}$ & $0,313 \mathrm{a}$ \\
\hline Ab 500 ppm & $0,373 \mathrm{a}$ & $0,422 \mathrm{a}$ & $0,456 \mathrm{a}$ & $0,380 \mathrm{a}$ & $0,266 \mathrm{a}$ \\
\hline Ab 1000 ppm & $0,301 \mathrm{a}$ & $0,346 \mathrm{a}$ & $0,375 \mathrm{a}$ & $0,326 \mathrm{a}$ & $0,323 \mathrm{a}$ \\
\hline Fungicida* & $0,342 \mathrm{a}$ & $0,312 \mathrm{a}$ & $0,312 \mathrm{a}$ & $0,300 \mathrm{a}$ & $0,228 \mathrm{a}$ \\
\hline Testemunha** & $0,244 \mathrm{a}$ & $0,251 \mathrm{a}$ & $0,091 \mathrm{a}$ & $0,000 \mathrm{~b}$ & $0,000 \mathrm{~b}$ \\
\hline DMS & 0,245 & 0,320 & 0,342 & 0,207 & 0,176 \\
\hline
\end{tabular}

Médias seguidas das mesmas letras não diferem entre si na coluna (minúsculas) pelo teste de Tukey a $5 \%$ de probabilidade. Produto comercial acibenzolar-S-metil (ASM), *agroquímico e **testemunha - água destilada e esterilizada. Concentrações utilizadas: $10,100,500$ e 1000 ppm (Ab), 200 mg . L ${ }^{-1}$ (ASM) e Mancozeb ${ }^{\circledR}\left(250\right.$ g.ha $\left.^{-1}\right)$, respectivamente. P1, P2, P3, P4 e P5 períodos em horas (192, 96, 48, 24, 0 respectivamente) entre a aplicação dos tratamentos e a inoculação com o patógeno.

Tabela 4. Atividade de fenilalanina amônia-liase a partir de diferentes concentraçõesdo extrato etanólico de $A$. blanchetti em diferentes intervalos de aplicação. Areia - PB, 2011.

\begin{tabular}{|c|c|c|c|c|c|}
\hline Tratamentos & \multicolumn{5}{|c|}{ Intervalos de aplicação $^{1}$} \\
\hline Ab 100 ppm & $0,033 \mathrm{~b}$ & $0,050 \mathrm{~b}$ & $0,140 \mathrm{ab}$ & $0,010 \mathrm{~b}$ & $0,005 \mathrm{a}$ \\
\hline Ab 500 ppm & $0,030 \mathrm{~b}$ & $0,036 \mathrm{~b}$ & $0,040 \mathrm{~b}$ & $0,050 \mathrm{ab}$ & $0,050 \mathrm{a}$ \\
\hline Fungicida & $0,050 \mathrm{~b}$ & $0,010 \mathrm{~b}$ & $0,073 \mathrm{~b}$ & $0,023 \mathrm{~b}$ & $0,002 \mathrm{a}$ \\
\hline Testemunha & $0,033 \mathrm{~b}$ & $0,036 \mathrm{~b}$ & $0,040 \mathrm{~b}$ & $0,023 \mathrm{~b}$ & $0,023 \mathrm{a}$ \\
\hline DMS & 0,176 & 0,052 & 0,117 & 0,105 & 0,082 \\
\hline
\end{tabular}

*Médias seguidas de mesma letra nas colunas não diferem entre si pelo teste de Tukey a 5 \% de probabilidade. Produto comercial acibenzolar-Smetil (ASM), *agroquímico e **testemunha - água destilada e esterilizada. Concentrações utilizadas: 10, 100, 500 e 1000 ppm (Ab), 200 mg . $\mathrm{L}^{-1}$ (ASM) e 250 g.ha $^{-1}\left(\right.$ Mancozeb $\left.^{\circledR}\right)$ respectivamente. P1, P2, P3, P4 e P5 períodos em horas (192, 96, 48, 24, 0 respectivamente) entre a aplicação dos tratamentos e a inoculação com o patógeno. 
resultados promissores na ativação de resposta de defesa contra $C$. eragrostidis (Tabela 4).

Analisando os resultados, para o intervalo de aplicação P1 (192 $\mathrm{h}$ antes da inoculação do patógeno), o ASM foi o tratamento que proporcionou maiores níveis de atividade da FAL, com diferença significativa em relação aos demais tratamentos. Para os intervalos P2, $\mathrm{P} 3$ e P4 o tratamento Ab 1000ppm foi superior aos demais tratamentos inclusive para ASM e fungicida, na ativação da enzima FAL.

Segundo Goellner \& Conrath (11) a expressão de indução não é imediata, havendo a necessidade de um determinado período para que a planta atinja o estado de indução, já que a expressão pela planta de RSA ou resistência sistêmica induzida (RSI) pode demorar de alguns dias até cerca de uma semana. A indução de resistência caracterizase pela ativação de mecanismos bioquímicos, que podem envolver a biossíntese e aumento na atividade de algumas enzimas dentre elas a peroxidase, $\beta$-1,3-glucanase e fenilalanina amônia liase (4).

Não houve ação fungitóxica direta do extrato etanólico de A. blanchetti e do acibenzolar-S-metil (ASM) no controle de $C$. eragrostidis in vitro. O extrato etanólico de A. blanchetti e o ASM promoveram o aumento na atividade das enzimas peroxidases, fenilalanina amônia-liase e $\beta$-1,3-glucanase. O extrato etanólico de $A$. blanchetti e o ASM, aplicados antes da inoculação com o patógeno, pré-condicionaram plantas de inhame a mecanismos de defesa induzida.

\section{AGRADECIMENTOS}

A CAPES pela concessão das bolsas de pós-doutorado e mestrado.

\section{REFERÊNCIAS}

1. Ahmed, F.; Meah, M.B.; Yasmin, F. Isolation of Phomopsis inhibitory fraction of Allamanda extract. Journal Environment Science \& Natural Resources, Bangladesh, v.5, n.2, p.199-203, 2012.

2. Alves, A.O.; Andrade, G.R.; Medeiros, D.B.; Xavier, A.S.; Bezerra Neto, E.; Barreto, L.P. Atividade da fenilalanina amônia liase em aceroleiras submetidas ao estresse hídrico. In: IX Jornada de Ensino, Pesquisa e Extensão - JEPEX, 9., 2009, Recife. Anais. Recife: UFRPE, 2009, p.1-3.

3. Barros, J.S.G.; Gomes, E.C.S.; Cavalcanti, L.S. Efeito de extratos de Allamanda blanchetti no controle de Alternaria brassicicola em mudas de couve-manteiga. Revista Caatinga, Mossoró, v.28, n.3, p.36-46, 2015.

4. Bertoncelli, D.J.; Mazaro, S.M.; Rocha, R.C.D.S.; Possenti, J.C.; Wagner Júnior, A. Acibenzolar-S-metil na indução de resistência de tomateiro e controle de Rhizoctonia solani Kuhn in vitro. Brazilian Journal of Applied Technology for Agricultural Science, Guarapuava, v.8, n.2, p.43-50, 2015.

5. Bezerra-Silva, G.C.D.; Vendramin, J.D.; Silva, M.A.; Dias, C.T.S. Efeito de extratos orgânicos de Meliaceae sobre Bemisia tabaci (Gennadius) biótipo b em tomateiro. Arquivos do Instituto Biológico, São Paulo, v.77, n.3, p.477-485, 2010.

6. Boava, L.P.; Kuhn, O.J.; Pascholati, S.F.; Di Piero, R.M.; Furtado, E.L. Efeito de indutores bióticos e abióticos na atividade de quitinase e peroxidase e no controle da ferrugem causada por Puccinia psidii em eucalipto. Summa Phytopathologica, Botucatu, v.36, n.2, p.168-172, 2010.

7. Brito, N.M.; Nascimento, L.C. Potencial fungitóxico de extratos vegetais sobre Curvularia eragrostidis (P. Henn.) Meyer in vitro. Revista Brasileira de Plantas Medicinais, São Paulo, v.17, n.2, p.230-238, 2015.

8. Cavalcanti, F.R.; Resende, M.L.V.; Zacaroni, A.B.; Ribeiro Júnior, P.M.; Costa, J.C.B.; Souza, R.M. Acibenzolar-S-metil e Ecolife ${ }^{\circledR}$ na indução de respostas de defesa do tomateiro contra a mancha bacteriana (Xanthomonas vesicatoria). Fitopatologia Brasileira, São Paulo, v.31, p.372-380, 2006.

9. Domingues, R.J.; Souza, J.D.F.; Töfoli, J.G.; Matheus, D.R. Ação “in vitro" de extratos vegetais sobre Colletotrichum acutatum, Alternaria solani e Sclerotium rolfsii. Arquivos do Instituto Biológico, São Paulo, v.76, n.4, p.643-649, 2009.

10. Faustina Dufie, W.M.; Oduro, I.; Ellis, W.O.; Asiedu, R.; Maziya-Dixon, B. Potential health benefits of water yam (Dioscorea alata). Food and Function, London, v.4, n.10, p.1496-501, 2013.

11. Goellner, K.; Conrath, U. Priming: it's all the world to induced disease resistance. European Journal of Plant Pathology, Switzerland, v.121, p.233-242, 2008

12. Govindappa, M.; Umesha, S.; Lokesh, S. Adathoda vasica leaf extract induces resistance in rice against bacterial leaf blight disease (Xanthomonas oryzae pv. oryzae). International Journal of Plant Physiology and Biochemistry, Egypt, v.3, n.1, p.6-14, 2011.

13. Graebner, I. B. Estudos dos constituintes químicos isolados de plantas medicinais da região do Vale do Purus no Acre (Amazônia). 2003. 113f Tese (Doutorado em Química/Química Orgânica) - Universidade Federal de Santa Maria, Santa Maria.

14. Guimarães, L.M.P.; Pedrosa, E.M.R.; Coelho, R.S.B.; Couto, E.F.; Maranhão, S.R.V.L.; Chaves, A. Eficiência e atividade enzimática elicitada por metil jasmonato e silicato de potássio em cana-de-açúcar parasitada por Meloidogyne incognita. Summa Phytopathologica, Botucatu, v.36, n.1, p.11-15, 2010.

15. Kuhn, O.J; Pascholati, S.F. Fitness cost of induced resistance in bean plants by the rhizobacteria Bacillus cereus or acibenzolar-S-methyl: enzymes activities, phenol and lignin synthesis, and biomass. Summa Phytopathologica, Botucatu, v.36, n.2, p.107-114, 2010.

16. Llorens, E.; García-Agustín, P.; Lapeña, L. Advances in induced resistance by natural compounds: towars new options for woody crop protection. Scientia Agricola, Maringá, v.74, n.1, p.90-100, 2017.

17. Medeiros, J.G.F.; Araújo Neto, A.C.; Menezes, N.P.C.; Nascimento, L.C. Sanidade e germinação de sementes de Clitoria fairchildiana tratadas com extratos de plantas. Pesquisa Florestal Brasileira, Colombo, v.33, n.76, p.403-408, 2013.

18. Michereff, S.J.; Noronha, M.A.; Maffia, L.A. Tamanho de amostras para avaliação da severidade da queima das folhas do inhame no campo. Summa Phytopathologica, Botucatu, v.34, n.2, p.189-191, 2008.

19. Moreira, C.G.A.; Schwan-Estrada, K.R.F.; Bonaldo, S.M.; Stangarlin, J.R.; Cruz, M.E. Caracterização parcial de frações obtidas de extratos de Cymbopogon nardus com atividade elicitora de fitoalexinas em sorgo e soja e efeito sobre Colletotrichum lagenarium. Summa Phytopathologica, Botucatu, v.34, n.4, p.332-337, 2008.

20. Noronha, M.A. Intensidade da queima das folhas do inhame no Estado de Alagoas. Alagoas: Embrapa, 2016. (Documento técnico, 172).

21. Paul, A.; Raychaudhuri, S.S. Medicinal uses and molecular identification of two Momordica charantia varieties - a review. Electronic Journal of Biology, Delaware, v.6, n.2, p.43-51, 2010.

22. Oliveira, A.P.; Barbosa, L.J.N.; Pereira, W.E.; Silva, J.E.L.; Oliveira, A.N.P. Produção de rizóforos comerciais de inhame em função de doses de nitrogênio. Horticultura Brasileira, Brasília, DF, v.25, p.73-76, 2007.

23. Silva, J.L.; Souza, P.E.; Monteiro, F.P.; Freitas, M.L.O.; Silva Júnior, M.B.; Belna, L.L. Antifungal activity using medicinal plant extracts against pathogens of coffee tree. Revista Brasileira de Plantas Medicinais., São Paulo, v.16, n.3, p.539-544, 2014.

24. Stangarlin, J.R.; Kuhn, O.J.; Toledo, M.V.; Portz, R.L.; Schwan-Estrada, K.R.F.; Pascholati, S.F. A defesa vegetal contra fitopatógenos. Scientia Agraria Paranaenis, Cascavel, v.10, n.1, p.18-46, 2011.

25. Wordell Filho, J.A.; Martins, D.A; Stadnik, M.J. Aplicação foliar de tratamentos para o controle do míldio e da podridão-de-escamas de bulbos de cebola. Horticultura Brasileira, São Paulo, v.25, p.544-549, 2007. 